\title{
DESIGN AND DEVELOPMENT OF A NEW APPROACH TO WRIST REHABILITATION
}

\author{
Ana Oliveira ${ }^{1}$, João Freitas ${ }^{2}$, Eurico Seabra ${ }^{3}$, Luís F. Silva ${ }^{4}$, Hélder Puga ${ }^{5}$ \\ Department of Mechanical Engineering, School of Engineering, University of Minho, 4800-058 Guimarães, Portugal \\ id7789@alunos.uminho.pt,a65394@alunos.uminho.pt,eseabra@dem.uminho.pt \\ lffsilva@dem.uminho.pt,puga@dem.uminho.pt
}

\begin{abstract}
Wrist injuries are a very common type of pathology that can compromise most daily tasks. Conventional therapy is dependent on the availability of physiotherapists as well as devices designed for this purpose. Conventional devices do not accompany the patient throughout their rehabilitation process, requiring their constant replacement. Vibratory therapies emerged in recent years and have demonstrated several benefits in this area. However, there are few vibratory devices designed for wrist rehabilitation. In this paper, we propose two different portable and active models for wrist rehabilitation based on vibratory therapy for wrist rehabilitation. The first model has a cylindrical shape and the second model has a dumbbell shape. The results obtained showed that vibratory therapy can assist the wrist rehabilitation because it promoted improvements in joint amplitude gain in all wrist movements. Furthermore, the second device demonstrated higher joint gains than the first device. In addition, the results obtained from the measurement of accelerations demonstrate that the natural frequencies of both devices are adequate for wrist and forearm rehabilitation as well as the mode of vibration. There are differences between what the simulations predicted and what was obtained in practice in terms of natural frequency values.
\end{abstract}

Keywords: Wrist, Medical device, Rehabilitation, Vibration, Biomechanics, Modelling.

\section{Introduction}

Wrist injuries are very common in most of population, being a type of pathology that entails several complications in performing daily tasks. The pathologies that can affect the normal performance of the wrist consist in fractures, tendinitis, and neurological diseases [1]. Patients that encompass this, have its movements compromised, such as flexion-extension and radial-ulnar deviation of the wrist and pronation-supination of the forearm [2]. Therefore, developing methodologies that accelerate patient recovery is an emerging problem.

The conventional wrist rehabilitation process is based on physiotherapy sessions that comprise three rehabilitation components: pain relief, muscle strengthening, and joint amplitude gain. The process of wrist rehabilitation should encompass all these components to allow recovery of all movements of the wrist and forearm [1]. Normally, to complete these procedures is necessary the aid of the therapist, but the availability of the therapists is a problem that impairs the rehabilitation [3]. Therefore, the development of autonomous devices that enable full recovery of the wrist not only in clinics but elsewhere is a growing need.

Current wrist rehabilitation devices that are used in rehabilitation clinics and hospitals mainly consist in springs, dumbbells, elastics, balls, bars, pedals, finger ladders and finger nets. These devices are characterized by its simplicity, ease of use, low price, and portability. However, most of these devices only provide one type of movement, and their replacement by another device is required to strengthen another movement. In addition, these devices only have passive functioning, not accompanying the patient throughout his rehabilitation process, which remains a problem. Therefore, there is a need for both active and mixed devices $[1,4]$.

To solve the limitations of marketed devices used in rehabilitation clinics, new devices, therapies, and systems have been proposed in recent years and there are some classes that stand out, such as virtual reality therapies [5-7], exoskeletons, gloves [3, 8, 9] and vibratory therapies $[10,11]$. In general, the degree of complexity of these devices increases compared to conventional devices, as well as its price. In addition, they are mostly non-portable limiting rehabilitation to clinics. The degree of difficulty of each exercise is adapted to the clinical condition of each patient, allowing appropriate therapy, and adjusted to the patient's progress, which is crucial to the success of rehabilitation $[1,4]$.

The virtual reality therapies allow the simulation of daily tasks through games and songs in a 
simulated environment. These systems allow a diversified and exciting rehabilitation for the patient, but they do not enable the continuation of therapy outside the rehabilitation clinics [4]. The BloBo Bluetooth Ball and CRAMER are examples of this type of therapy that through a diversified and attractive game/song allow the exercise of all movements of the wrist [5, 7].

In turn, the exoskeletons and gloves are portable, making the rehabilitation not confined just to clinics. These devices are very useful for fingers rehabilitation since they replicate all the wrist movements. Unfortunately, they do not allow the rehabilitation of the wrist and forearm [4]. Many authors focused their study on these devices which normally consists of pneumatic actuators of variable stiffness coupled with gloves. These allow different conformations to the hand and subsequent manipulation of objects $[3,9,12]$.

In recent years, vibratory therapies have emerged as potential helping aids to rehabilitation processes. These have demonstrated improvements in patients with multiple sclerosis, in recovery of muscle strength and function, in preventing bone loss and even in accelerating the healing of the bone without inhibiting the healing of the ligament in traumatic lesions [13-17]. Other authors have shown that the induction of vibration to the wrist can aid in the rehabilitation process after the occurrence of a traumatic injury. For this, they used a vibrating platform and a compressed air sander to induce vibration to the wrist [10]. However, there is a need to design targeted devices for wrist rehabilitation. In addition, further studies will be required to verify that the natural frequencies induced by this type of vibration do not match with the hand and arm resonance frequencies, which are between 20 and 70 $\mathrm{Hz}[18,19]$. Other authors have developed a device that has two components, one for wrist rehabilitation through the reproduction of the wrist movements and another for proprioception exercises and relaxation. With this device it is possible to obtain the gain of amplitude for each movement and increase of amplitude that the patient is capable to perform [11].

In this paper we propose two geometries for a portable active device that uses vibration for wrist rehabilitation. This device acts on all rehabilitation components and can assist all movements of the wrist and forearm. This work will focus on the active component of the device, although it may also work in passive or mixed mode.

\section{Materials and Methods}

The geometries proposed for the devices were designed to have an attractive shape (cylindrical and dumbbell shape) capable of encouraging the patient to use it. These devices have an ergonomic cylindrical handle, whose dimensioning was carried out considering the anthropometric measurements of the human hand [1].

\section{Geometric Models}

The first proposed model has a cylindrical shape and a very simple structure (Figure $1 \mathrm{a}$ ). This model consists of a tube with a diameter of $26 \mathrm{~mm}$ and a length of $100 \mathrm{~mm}$. Within this tube are coupled two motors, in the same direction but with opposite paths, one at each end with the respective offset mass attached by the shaft. The offset masses have $10 \mathrm{~mm}$ of diameter and $5 \mathrm{~mm}$ of length.

The second model was designed to present a dumbbell shape (Figure 1b). This model also features two motors with the offset masses joined by the respective shafts. In this case, the motors are no longer aligned by the same axis of the device, but in a perpendicular direction. In this model, the cylindrical handle has $28 \mathrm{~mm}$ of diameter and 100 $\mathrm{mm}$ of length. Each end has a cylinder with $30 \mathrm{~mm}$ of diameter and $55 \mathrm{~mm}$ of length, perpendicular to the main axis of the handle. Therefore, it is here that the motors and their offset masses are housed. The offset masses have $12 \mathrm{~mm}$ of diameter and $8 \mathrm{~mm}$ of length.

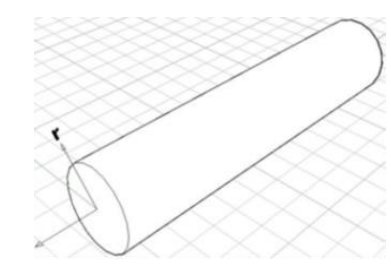

(a)

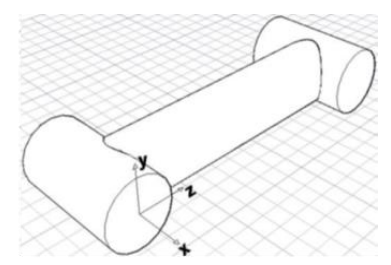

(b)
Figure 1: Geometric Models for the First Prototype (a) and for the Second Prototype (b)

\section{Static Numeric Simulation}

To find an ideal geometry for the device, in terms of modes and frequencies of vibration versus cylindrical handle length of the model, a numerical simulation was performed in COMSOL Multiphysics ${ }^{\circledR} 5.1$ software (COMSOL inc., 2015). We perform static simulations, and so we use simplified device models. Therefore, instead of motors, shafts, and offset masses, we use only two large masses at the ends of the devices.

The material used in the simulations was aluminum 6063 (density $=2700 \mathrm{~kg} / \mathrm{m}^{3}$; Young's modulus $=69 \mathrm{GPa}$; Poisson's ratio $=0,33$ ). For the simulations it was considered that the body was free in space, with no external fixation point, the connections between the body and the motors are rigid and its initial conditions were considered as static (acceleration $=0 \mathrm{~m} / \mathrm{s}^{2} ;$ velocity $=0 \mathrm{~m} / \mathrm{s}$; displacement $=0 \mathrm{~m}$ ).

The nodes generated by the mesh were tetrahedral (the first model has 40490 nodes, and the second model has 18864 nodes). 
Both models were simulated for their eigenfrequencies, iterating over various lengths of the geometry of the cylindrical handles between 100 and $160 \mathrm{~mm}$.

\section{Tests on Patients}

The two prototypes were tested in nine patients with wrist pathologies who attended physical therapy sessions. All patients had different clinical conditions and backgrounds (see Table 1). Each patient underwent a fifteen-minute vibration therapy session on three consecutive days with one of the devices. After that, patients rested two days of vibratory therapy. Then, these patients were submitted to a new fifteen-minute treatment on three consecutive days, but with the other device. The patients P4, P5, P6, P7, and P9 were first submitted to the first prototype and then to the second one, while the patients P1, P2, P3, and P8 were first submitted to the second prototype and then to the first one. Joint amplitude measurements were performed before the vibratory therapy, after a single session of vibratory therapy, after three days of vibratory therapy, after two days of rest and after six sessions of vibratory therapy. A goniometer was used to carry out the measurements.

\section{Accelerations}

Acceleration measurements allow the study of the maximum accelerations to which patients are subjected, as well as the corresponding frequencies. Therefore, the accelerations were measured in both devices. For this procedure a variable power supply was required, and the motors of the devices were supplied with a voltage of $4 \mathrm{~V}$. In each of the devices was placed an accelerometer and its position varied according to the measuring axes shown in Figure 1. Due to the characteristics of the first device, measurement was only possible on one axis, while in the second device measurements were taken on the three axes.

The accelerometer was connected to a signal conditioning board and then to a data acquisition board, making it possible to visualize the results on a computer. The software used was the LabView 7.1 (from National Instruments).

For measurements, two healthy individuals, one female and one male, grasped the cylindrical handle of each one of the devices to see if the gender of an individual causes significant differences in the accelerations.

Table 1. Clinical Conditions of the Study Participants

\begin{tabular}{|l|l|l|l|l|}
\cline { 2 - 5 } \multicolumn{1}{c|}{} & Gender & $\begin{array}{l}\text { Age } \\
\text { (Years) }\end{array}$ & $\begin{array}{l}\text { Patholo- } \\
\text { gies }\end{array}$ & $\begin{array}{l}\text { Additional } \\
\text { Notes }\end{array}$ \\
\hline P1 & Female & 72 & CT & LS, PS, 23FS \\
\hline P2 & Female & 31 & DQ & LS, AS, 1FS \\
\hline P3 & Female & 64 & DQ & RS, AS, 72FS \\
\hline
\end{tabular}

\begin{tabular}{|l|l|l|l|l|}
\hline P4 & Male & 55 & TI & LS, AS, 28FS \\
\hline P5 & Male & 25 & CT & LS, PS, 25FS \\
\hline P6 & Female & 83 & T & RS, PS, 15FS \\
\hline P7 & Male & 34 & DQ & RS, AS, 9FS \\
\hline P8 & Female & 46 & SFS & LS, AS, 15FS \\
\hline P9 & Female & 59 & CF & LS, AS, 25FS \\
\hline
\end{tabular}

\section{Results and Discussion}

All the results obtained in this work are presented in this section, from the numerical simulation to the practical experimentation of the devices and respective accelerations.

\section{Static Numeric Simulation}

The mode of vibration is important to understand the movement/behavior of the devices. The flexion mode was the first mode of vibration obtained (see Figure 2), which is desirable because it allows the flexion movement to the wrist, which can be combined with the radial-ulnar deviation and pronation-supination movements. It is expected that the behavior of the devices is a combined movement in practice. Thus, no isolated movements will be observed (only one degree of freedom), but a surrounding movement of three degrees of freedom.

Since the flexion mode is the first found mode, it occurs at lower frequencies than the other succeeding modes, which is a positive aspect. Vibration modes of torsion, compression, extension, or rigid would not cause the desired movement.

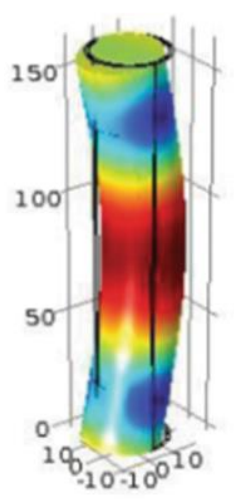

(a)

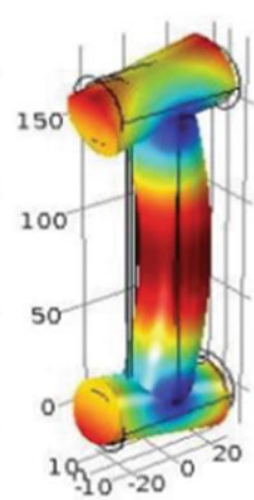

(b)
Figure 2: First Mode of Vibration (Flexion): (a) for the First Model and (b) for the Second Model.

These results also suggest the occurrence of a displacement during the vibration mode of both models. This aspect may be useful in practice, as this may cause an increase in the amplitude of the wrist joint movements.

In Table 2 we can find the eigenfrequencies obtained as the length of the cylindrical handle of each of the devices has been increased for the first vibration mode. 
Table 2. Relationship between the Device Length and Eigenfrequency Values for Both Models

\begin{tabular}{|l|l|l|l|l|}
\hline First model \\
\hline Length (mm) & 100 & 120 & 140 & 160 \\
\hline $\begin{array}{l}\text { Eigenfrequency } \\
\text { (Hz) }\end{array}$ & 8092 & 6033 & 4631 & 3647 \\
\hline Second Model \\
\hline Length (mm) & 100 & 120 & 140 & 160 \\
\hline $\begin{array}{l}\text { Eigenfrequency } \\
(\mathrm{Hz})\end{array}$ & 4169 & 3484 & 2930 & 2482 \\
\hline
\end{tabular}

These results suggest that as the length of the cylindrical handle of the device is increased, the eigenfrequency values decrease. Furthermore, there is a tendency for higher frequencies with the first device than with the second device.

In any case, the resonance frequencies of the hand and arm are achieved (20 to $70 \mathrm{~Hz}$ ), because the frequencies obtained are in a much higher range $[18,19]$.

\section{Tests on Patients}

The total joint gains obtained for each movement as a result of the therapy with both prototypes (six sessions of vibratory therapy) are shown in the Table 3.

There was an increase in joint amplitude gain after therapy with both prototypes, suggesting that physiotherapy in combination with vibratory therapy promotes an increase in joint amplitude in all movements of the wrist and forearm in both genders. The increase in joint amplitude was null in pronation and supination in the male gender because the patients already had the movement completely re-established. These improvements were greater than those obtained by other work for both genders [18], suggesting that the vibratory therapy is promising for wrist rehabilitation. Another study [10] achieved a greater increase in joint amplitude for the flexion movement with vibration therapy but used a longer exposure time and vibration frequencies that match with the resonance frequencies of the wrist and forearm which should be avoided $[18,19]$.

A great dispersion of results can also be observed for flexion, extension, pronation, and supination (see Table 3).

Table 3. Total Joint Gain, in Parenthesis are the Values for the Patients that did not have a Fully Recovered

\begin{tabular}{|c|c|c|c|c|}
\hline \multirow{3}{*}{ Movement } & \multirow{2}{*}{\multicolumn{2}{|c|}{ Female }} & \multirow{2}{*}{\multicolumn{2}{|c|}{ Male }} \\
\hline & & & & \\
\hline & $\mathrm{M}$ & SD & $\mathrm{M}$ & SD \\
\hline Flexion & $17,3^{\circ}$ & $8,6^{\circ}$ & $14,7^{\circ}$ & $11,9^{\circ}$ \\
\hline Extension & $16,5^{\circ}$ & $10,2^{\circ}$ & $12,3^{\circ}$ & $9,3^{\circ}$ \\
\hline
\end{tabular}

\footnotetext{
${ }^{1} \mathrm{M}$ - Mean; SD - Standard Deviation.
}

\begin{tabular}{|l|l|l|l|l|}
\hline $\begin{array}{l}\text { Radial } \\
\text { deviation }\end{array}$ & $\begin{array}{l}4,3^{\circ} \\
\left(5,2^{\circ}\right)\end{array}$ & $\begin{array}{l}3,1^{\circ} \\
\left(2,5^{\circ}\right)\end{array}$ & $5,0^{\circ}$ & $2,0^{\circ}$ \\
\hline $\begin{array}{l}\text { Ulnar } \\
\text { deviation }\end{array}$ & $8,5^{\circ}$ & $2,8^{\circ}$ & $10,0^{\circ}$ & $3,0^{\circ}$ \\
\hline Pronation & $\begin{array}{l}9,2^{\circ} \\
\left(27,5^{\circ}\right)\end{array}$ & $\begin{array}{l}20,1^{\circ} \\
\left(31,8^{\circ}\right)\end{array}$ & $0,0^{\circ}$ & $0,0^{\circ}$ \\
\hline Supination & $\begin{array}{l}11,2^{\circ} \\
\left(13,4^{\circ}\right)\end{array}$ & $\begin{array}{l}13,6^{\circ} \\
\left(13,9^{\circ}\right)\end{array}$ & $0,0^{\circ}$ & $0,0^{\circ}$ \\
\hline
\end{tabular}

The results of joint amplitude gain obtained after a single session of vibratory therapy without the interference of physiotherapy sessions are presented in the Table 4 for all movements and both genders.

Table 4. Joint Gain after a Single Session, in Parenthesis are the Values for the Patients that did not have a Fully Recovered Movement

\begin{tabular}{|l|l|l|l|l|}
\hline \multirow{2}{*}{ Movement } & \multicolumn{3}{|l|}{ Female } & \multicolumn{2}{l|}{ Male } \\
\cline { 2 - 5 } & $\mathrm{M}$ & $\mathrm{SD}$ & $\mathrm{M}$ & $\mathrm{SD}$ \\
\hline Flexion & $4,8^{\circ}$ & $4,7^{\circ}$ & $4,3^{\circ}$ & $0,6^{\circ}$ \\
\hline Extension & $5,3^{\circ}$ & $5,8^{\circ}$ & $2,3^{\circ}$ & $0,6^{\circ}$ \\
\hline $\begin{array}{l}\text { Radial } \\
\text { deviation }\end{array}$ & $\begin{array}{l}2,0^{\circ} \\
\left(2,4^{\circ}\right)\end{array}$ & $\begin{array}{l}1,8^{\circ} \\
\left(1,7^{\circ}\right)\end{array}$ & $2,0^{\circ}$ & $0,0^{\circ}$ \\
\hline $\begin{array}{l}\text { Ulnar } \\
\text { deviation }\end{array}$ & $3,3^{\circ}$ & $1,2^{\circ}$ & $2,3^{\circ}$ & $1,5^{\circ}$ \\
\hline Pronation & $\begin{array}{l}2,3^{\circ} \\
\left(7,0^{\circ}\right)\end{array}$ & $\begin{array}{l}4,8^{\circ} \\
\left(7,1^{\circ}\right)\end{array}$ & $0,0^{\circ}$ & $0,0^{\circ}$ \\
\hline Supination & $\begin{array}{l}3,2^{\circ} \\
\left(3,8^{\circ}\right)\end{array}$ & $\begin{array}{l}4,0^{\circ} \\
\left(4,1^{\circ}\right)\end{array}$ & $0,0^{\circ}$ & $0,0^{\circ}$ \\
\hline
\end{tabular}

A significant increase in joint amplitude has been demonstrated in all wrist and forearm movements after a single session of vibratory therapy for both genders, suggesting that even in the absence of physiotherapy, the vibration is able to strengthen the wrist and forearm movements. A great dispersion of results can also be observed for flexion, extension, pronation, and supination (see Table 4).

Table 5 shows the joint loss in the movements of the wrist and forearm after the two days of pause of vibratory therapy.

Table 5. Joint Loss after Pause in Vibratory Therapy, in Parenthesis are the Values for the Patients that did not have a Fully Recovered Movement

\begin{tabular}{|l|l|l|l|l|}
\hline \multirow{2}{*}{ Movement } & \multicolumn{3}{|l|}{ Female } & Male \\
\cline { 2 - 5 } & $\mathrm{M}$ & $\mathrm{SD}$ & $\mathrm{M}$ & $\mathrm{SD}$ \\
\hline Flexion & $1,2^{\circ}$ & $1,5^{\circ}$ & $3,7^{\circ}$ & $4,0^{\circ}$ \\
\hline Extension & $3,0^{\circ}$ & $2,8^{\circ}$ & $1,7^{\circ}$ & $2,1^{\circ}$ \\
\hline $\begin{array}{l}\text { Radial } \\
\text { deviation }\end{array}$ & $\begin{array}{l}1,7^{\circ} \\
\left(2,0^{\circ}\right)\end{array}$ & $\begin{array}{l}2,0^{\circ} \\
\left(2,0^{\circ}\right)\end{array}$ & $1,7^{\circ}$ & $1,5^{\circ}$ \\
\hline $\begin{array}{l}\text { Ulnar } \\
\text { deviation }\end{array}$ & $1,8^{\circ}$ & $1,0^{\circ}$ & $2,7^{\circ}$ & $0,6^{\circ}$ \\
\hline Pronation & $\begin{array}{l}0,0^{\circ} \\
\left(0,0^{\circ}\right)\end{array}$ & $\begin{array}{l}0,0^{\circ} \\
\left(0,0^{\circ}\right)\end{array}$ & $0,0^{\circ}$ & $0,0^{\circ}$ \\
\hline Supination & $\begin{array}{l}1,0^{\circ} \\
\left(1,2^{\circ}\right)\end{array}$ & $\begin{array}{l}1,7^{\circ} \\
\left(1,8^{\circ}\right)\end{array}$ & $0,0^{\circ}$ & $0,0^{\circ}$ \\
\hline
\end{tabular}


These results suggest that there is a little significant joint loss resulting from the pause in the vibratory therapy, except for the movement of pronation of the forearm in the female participants (there are no data for male pronation and supination movements). There were no significant differences between the two genders in the dispersion of results (see Table 5).

The joint gain obtained with each one of the prototypes was also studied and the results are shown in Tables 6 and 7 for the first and second devices, respectively. The joint gain resulting from the use of each of the prototypes was very similar. However, there seems to be a slight tendency for a greater increase in joint mobility with the second prototype. There is also a great dispersion of results for flexion, extension, pronation, and supination (see Tables 6 and 7).

\section{Accelerations}

Table 8 shows the peak frequencies obtained for each measurement axis and gender of the individual.

In this rehabilitation process the resonance frequencies of the hand and the arm should be avoided, which are between 20 and $70 \mathrm{~Hz}[18,19]$. In fact, the frequencies obtained in this work did not match with the resonance frequencies range. In addition, the frequencies obtained are not high, not compromising the health of the patients. Also, the results for both genders were similar.

Furthermore, it was verified that the frequency values resulting from the experimental analysis of the accelerations are inferior to those obtained in the numerical simulations. This difference between theoretical and practical results may be associated with the simplifications used in static simulation, as well as with the material used.

Table 6. Joint Gain for the First Prototype, in Parenthesis are the Values for the Patients that did not have a Fully Recovered Movement

\begin{tabular}{|l|l|l|l|l|}
\hline \multirow{2}{*}{ Movement } & \multicolumn{2}{|l|}{ Female } & \multicolumn{2}{l|}{ Male } \\
\cline { 2 - 5 } & $\mathrm{M}$ & $\mathrm{SD}$ & $\mathrm{M}$ & $\mathrm{SD}$ \\
\hline Flexion & $9,3^{\circ}$ & $5,0^{\circ}$ & $7,0^{\circ}$ & $2,6^{\circ}$ \\
\hline Extension & $11,5^{\circ}$ & $6,6^{\circ}$ & $4,3^{\circ}$ & $0,6^{\circ}$ \\
\hline $\begin{array}{l}\text { Radial } \\
\text { deviation }\end{array}$ & $\begin{array}{l}3,2^{\circ} \\
\left(3,8^{\circ}\right)\end{array}$ & $\begin{array}{l}2,7^{\circ} \\
\left(2,5^{\circ}\right)\end{array}$ & $3,3^{\circ}$ & $0,6^{\circ}$ \\
\hline $\begin{array}{l}\text { Ulnar } \\
\text { deviation }\end{array}$ & $4,0^{\circ}$ & $1,7^{\circ}$ & $5,3^{\circ}$ & $2,5^{\circ}$ \\
\hline $\begin{array}{l}\text { Pronation } \\
\left(11,5^{\circ}\right)\end{array}$ & $\begin{array}{l}8,9^{\circ} \\
\left(14,8^{\circ}\right)\end{array}$ & $0,0^{\circ}$ & $0,0^{\circ}$ \\
\hline Supination & $\begin{array}{l}5,2^{\circ} \\
\left(6,2^{\circ}\right)\end{array}$ & $\begin{array}{l}6,4^{\circ} \\
\left(6,6^{\circ}\right)\end{array}$ & $0,0^{\circ}$ & $0,0^{\circ}$ \\
\hline
\end{tabular}

Table 7. Joint Gain for the Second Prototype, in Parenthesis are the Values for the Patients that did not have a Fully Recovered Movement

\begin{tabular}{|l|l|l|l|l|}
\hline \multirow{2}{*}{ Movement } & \multicolumn{3}{|l|}{ Female } & \multicolumn{3}{l|}{ Male } \\
\cline { 2 - 5 } & $\mathrm{M}$ & $\mathrm{SD}$ & $\mathrm{M}$ & $\mathrm{SD}$ \\
\hline Flexion & $10,3^{\circ}$ & $8,2^{\circ}$ & $11,3^{\circ}$ & $8,1^{\circ}$ \\
\hline Extension & $8,0^{\circ}$ & $5,9^{\circ}$ & $9,7^{\circ}$ & $8,1^{\circ}$ \\
\hline $\begin{array}{l}\text { Radial } \\
\text { deviation }\end{array}$ & $\begin{array}{l}2,8^{\circ} \\
\left(3,4^{\circ}\right)\end{array}$ & $\begin{array}{l}2,0^{\circ} \\
\left(1,7^{\circ}\right)\end{array}$ & $3,3^{\circ}$ & $0,6^{\circ}$ \\
\hline $\begin{array}{l}\text { Ulnar } \\
\text { deviation }\end{array}$ & $6,3^{\circ}$ & $2,3^{\circ}$ & $7,3^{\circ}$ & $3,5^{\circ}$ \\
\hline Pronation & $\begin{array}{l}5,3^{\circ} \\
\left(16,0^{\circ}\right)\end{array}$ & $\begin{array}{l}11,2^{\circ} \\
\left(17,0^{\circ}\right)\end{array}$ & $0,0^{\circ}$ & $0,0^{\circ}$ \\
\hline Supination & $\begin{array}{l}7,0^{\circ} \\
\left(8,4^{\circ}\right)\end{array}$ & $\begin{array}{l}7,7^{\circ} \\
\left(7,7^{\circ}\right)\end{array}$ & $0,0^{\circ}$ & $0,0^{\circ}$ \\
\hline
\end{tabular}

Table 8. Peak of Accelerations

\begin{tabular}{|c|c|c|c|}
\hline & Frequency (Hz) \\
\hline \multirow{2}{*}{$\begin{array}{l}\text { First } \\
\text { prototype }\end{array}$} & \multicolumn{2}{|c|}{ Female } & 84,0 \\
\hline & \multicolumn{2}{|l|}{ Male } & 82,2 \\
\hline \multirow{6}{*}{$\begin{array}{l}\text { Second } \\
\text { prototype }\end{array}$} & \multirow{2}{*}{$\mathrm{X}$ axis } & Female & 83,2 \\
\hline & & Male & 79,6 \\
\hline & \multirow{2}{*}{ Y axis } & Female & 78,4 \\
\hline & & Male & 80,2 \\
\hline & \multirow{2}{*}{$\mathrm{Z}$ axis } & Female & 84,0 \\
\hline & & Male & 82,2 \\
\hline
\end{tabular}

\section{Conclusions and Further Research}

In this work, the vibratory therapy was shown to be an important aspect of the rehabilitation of the wrist and forearm. Both prototypes showed therapeutic benefit, although greater joint mobility was observed with the second prototype.

Furthermore, the obtained frequencies were not high, and the range of resonance frequencies of the hand and the arm was safeguarded. However, there was a difference between the results obtained in the numerical simulations and the ones obtained in practice, in terms of vibration frequencies.

Although this work has been focused on the active component of the device, it can also be used in a passive mode (without vibration, the patient provides the force to move the device) or in a mixed mode. Thus, it can be adapted to the needs and capacities of each patient.

The future research involves the optimization of prototypes, with the realization of numerical simulations of dynamic nature, in materials suitable for construction and with all the particularities of the final devices. In addition, new prototypes should be built in materials suitable for industrialization. New tests with more accelerometers or with three-axis accelerometers should be performed, as well as a virtual reconstruction of the movement. Moreover, clinical tests should be conducted in a larger number of patients and the sample of patients should be standardized (same type of pathologies and clinical conditions). 


\section{References}

[1] Oliveira, A. C. C. (2017). Desenvolvimento e teste de um novo dispositivo para reabilitação do pulso. Dissertation of Integrated Master in Biomedical Engineering, School of Engineering, University of Minho

[2] Garratt, B. J. (2009). The development of a wrist rehabilitation device for movement therapy. Bachelor of Engineering, Faculty of Engineering and Surveying, University of Southern Queensland

[3] Bartlett, N. W., Lyau, V., Raiford, W. A., Holland, D., Gafford, J. B., Ellis, T. D., and Walsh, C. J. (2015). A soft robotic orthosis for wrist rehabilitation. Journal of Medical Devices, 9(3), 030918

[4] Oliveira, A., Seabra, E., Silva, L. F., and Puga, H. (2018). Literature Review and Analysis of Wrist Reabilitation Devices. In Araújo M. (eds) International Conference on Production Economics and Project Evaluation. ICOPEV 2018. Thomson Reuters Conference Proceedings Citation Index (pp. 23-28). Elsevier

[5] Hsieh, W. M., Hwang, Y. S., Chen, S. C., Tan, S. Y., Chen, C. C., and Chen, Y. L. (2016). Application of the Blobo bluetooth ball in wrist rehabilitation training. Journal of physical therapy science, 28(1), 27-32

[6] Tsoupikova, D., Stoykov, N. S., Corrigan, M., Thielbar, K., Vick, R., Li, Y., Triandafilou, K., Preuss, F., and Kamper, D. (2015). Virtual immersion for post-stroke hand rehabilitation therapy. Annals of biomedical engineering, 43(2), 467-477

[7] Spencer, S. J., Klein, J., Minakata, K., Le, V., Bobrow, J. E., and Reinkensmeyer, D. J. (2008). A low cost parallel robot and trajectory optimization method for wrist and forearm rehabilitation using the Wii. In International Conference on Biomedical Robotics and Biomechatronics. BioRob 2008. Proceedings of the 2nd Biennial IEEE/RAS-EMBS (pp. 869-874). IEEE

[8] Polygerinos, P., Wang, Z., Galloway, K. C., Wood, R. J., and Walsh, C. J. (2015). Soft robotic glove for combined assistance and at-home rehabilitation. Robotics and Autonomous Systems, 73, 135-143

[9] Yap, H. K., Lim, J. H., Nasrallah, F., Goh, J. C., and Yeow, R. C. (2015). A soft exoskeleton for hand assistive and rehabilitation application using pneumatic actuators with variable stiffness. In International Conference on Robotics and Automation (ICRA). 2015 IEEE (pp. 4967-4972). IEEE

[10] Brewin, M. P., Bexon, C. J., and Tucker, S. C. (2017). A case report on the use of vibration to improve soft tissue extensibility after major trauma. Journal of Hand Therapy, 30(3), 367371
[11] Seabra, E., Silva, L. F., Ferreira, R., and Leiras, V. (2019). Design, Development and Construction of a New Medical Wrist Rehabilitation Device: A Project Review. In Machado J., Soares F., Veiga G. (eds) Innovation, Engineering and Entrepreneurship. HELIX 2018. Lecture Notes in Electrical Engineering (pp. 199-205), vol 505. Springer, Cham

[12] Polygerinos, P., Lyne, S., Wang, Z., Nicolini, L. F., Mosadegh, B., Whitesides, G. M., \& Walsh, C. J. (2013). Towards a soft pneumatic glove for hand rehabilitation. In 2013 IEEE/RSJ International Conference on Intelligent Robots and Systems (IROS) (pp. 1512-1517). IEEE

[13] Bily, W., Franz, C., Trimmel, L., Loefler, S., Cvecka, J., Zampieri, S., Kasche, W., Sarabon, N., Zenz, P., and Kern, H. (2016). Effects of legpress training with moderate vibration on muscle strength, pain, and function after total knee arthroplasty: a randomized controlled trial. Archives of physical medicine and rehabilitation, 97(6), 857-865

[14] Camerota, F., Celletti, C., Di Sipio, E., De Fino, C., Simbolotti, C., Germanotta, M., Mirabella, M., Padua, L., and Nociti, V. (2017). Focal muscle vibration, an effective rehabilitative approach in severe gait impairment due to multiple sclerosis. Journal of the neurological sciences, 372, 33-39

[15] Huang, Y., Luan, H., Sun, L., Bi, J., Wang, Y., and Fan, Y. (2017). Local vibration enhanced the efficacy of passive exercise on mitigating bone loss in hindlimb unloading rats. Acta Astronautica, 137, 373-381

[16] Pamukoff, D. N., Pietrosimone, B., Lewek, M. D., Ryan, E. D., Weinhold, P. S., Lee, D. R., and Blackburn, J. T. (2016). Whole-body and local muscle vibration immediately improve quadriceps function in individuals with anterior cruciate ligament reconstruction. Archives of physical medicine and rehabilitation, 97(7), 1121-1129

[17] Thompson, W. R., Keller, B. V., Davis, M. L., Dahners, L. E., and Weinhold, P. S. (2015). LowMagnitude, high-frequency vibration fails to accelerate ligament healing but stimulates collagen synthesis in the Achilles Tendon. Orthopaedic journal of sports medicine, 3(5), 2325967115585783

[18] Duarte, M. L. M., Misael, M. R., and Freitas Filho, L. E. (2002). Experimental evaluation of vibration comfort for a residential environment. In IMAC-XX: Conference and Exposition on Structural Dynamics. SPIE proceedings series (pp. 1376-1377). Society of Photo-Optical Instrumentation Engineers

[19] Mester, J., Kleinöder, H., and Yue, Z. (2006). Vibration training: benefits and risks. Journal of biomechanics, 39(6), 1056-1065 